\title{
TERREMOTOS: \\ ¿UNA OPORTUNIDAD PARA AVANZAR \\ LA AGENDA DE CADA GOBIERNO? \\ Ricardo Lagos Escobar
}




\section{RICARDO LAGOS ESCOBAR}

Abogado, Universidad de Chile, 1960.

Doctor en Economía, Universidad de Duke (1966). Secretario General de la Universidad de Chile entre 1969 y 1971. En 1973 pasa a desempeñarse como Secretario General de la Facultad Latinoamericana de Ciencias Sociales (FLACSO) con sede en Buenos Aires. En 1974 se traslada a Estados Unidos para ejercer como Profesor Visitante en la Universidad de Chapel Hill (Carolina del Norte). Entre 1990 y 1993 se desempeñó como Ministro de Educación bajo la presidencia de Patricio Aylwin. Entre 1994 y 1998, durante el mandato de Eduardo Frei RuizTagle, ocupó la cartera de Obras Públicas. El 16 de enero de 2000 fue elegido Presidente de la República, cargo que desempeñó hasta el 11 de marzo de 2006. El 13 de marzo de 2006 crea la Fundación Democracia y Desarrollo (FDD), de la cual es su presidente. 
"NADIE SABE CUÁNDO OCURRIRÁ un terremoto. Los sismólogos pueden anunciar posibles impactos, dados los desplazamientos de las placas tectónicas, pero no existe aún el sistema de alerta temprana y precisa. Lo que sí se sabe es que un terremoto reclamará respuestas inmediatas frente al desastre y obligará a gastos extraordinarios para el retorno a la normalidad"1.

En la historia de Chile la devastación, la intensidad y la sorpresa de los terremotos ha sido una constante. Pero las continuidades que los terremotos representan en nuestra historia desde la Colonia, por lo menos, no comienzan ni terminan en su frecuencia ni en su poder destructivo. Los terremotos generan siempre en Chile otro tipo de constantes: surge un sentimiento de unidad nacional frente a la catástrofe. La ciudadanía tiende a ordenarse en torno al Jefe del Estado. Así, a lo largo del siglo XX cada gran tragedia de esta naturaleza provocó una suerte de suspensión en la pugna política. Por ejemplo, cuando en 1960 tuvo lugar el terremoto más grande de los registrados por la humanidad, transformando drásticamente la geografía del sur de Chile, se declaró expresamente una tregua política por parte de todos los partidos, desde comunistas a conservadores. El Partido Comunista, que había presentado una acusación constitucional en contra de los ministros de Economía y Hacienda del presidente Alessandri, procedió a retirarla en aras de la unidad nacional.

En esos momentos todos los sectores entendían que era necesario deponer las banderas propias y buscar el interés común para enfrentar la catástrofe de la naturaleza. Ello ha ido formando una suerte de gran resiliencia por parte de la sociedad chilena. No es que sea posible acostumbrarse a los terremotos, porque es sencillamente imposible. Pero sí hay un entendimiento de que así se ha ido construyendo nuestro país a lo largo de la historia. El ritual es el mismo: sacar los escombros los primeros días, luego, la búsqueda de habitaciones de emergencia (algunas de las cuales duran hasta 20 años o más), y después la mirada larga para una reconstrucción que se engarza con el desarrollo de Chile.

1. Ricardo Lagos. "Chile respira profundo y encara la catástrofe". Clarín, Buenos Aires, marzo 7 de 2010. 
Así ha sido siempre. Lo que parece interesante analizar es que el terremoto en general contribuye a generar condiciones propicias para que el gobierno en ejercicio pueda avanzar en sus propios programas. Este es el análisis que se hace de una manera somera, pero a modo de hipótesis en las siguientes líneas.

Seis son los principales momentos de la historia de Chile que serán abordados en este análisis: el terremoto de 1906 en Valparaíso; el de 1928 en Talca; el de 1939 en Chillán; el de 1960 en Concepción y Valdivia; el de 1985 en el puerto de San Antonio y Melipilla; y el de 2010 en Cobquecura, que abarcó desde la Región Metropolitana hasta la Región de la Araucanía.

\section{VALPARAÍSO, 16 DE AGOSTO DE 1906 \\ Grado: 8.6 \\ Hora: dos movimientos sucesivos antes y después de las 20 horas \\ Víctimas: 2.300 muertos.}

Este gran terremoto fue similar por su intensidad y su localización próxima al Pacífico al sismo que el año anterior había ocurrido en San Francisco, Estados Unidos. El terremoto de 1906 se produce en pleno desarrollo del periodo conocido como República Parlamentaria, donde la rotación ministerial era intensa. Son los días finales del gobierno del presidente Germán Riesco, y Pedro Montt, que asumirá en septiembre de 1906, ya es presidente electo. Las medidas más urgentes, por cierto, son asumidas por Riesco. El gobierno consideró necesario declarar de inmediato el Estado de Sitio y, para mantener el orden público, entregó el control de la ciudad al Capitán de Navío Luis Gómez Carreño, quien se caracterizó por una mano extraordinariamente firme: para evitar los saqueos decretó fusilamientos en el acto o en un Tribunal Militar constituido de inmediato. Se habla de más de 2.300 muertos, de 20 mil heridos y toda la ciudad de Valparaíso destruida, incluidas las instalaciones portuarias. Todos los servicios básicos quedaron interrumpidos y a poco andar el terremoto fue seguido de numerosos incendios. El telegrama del intendente Enrique Larraín al Ministro del Interior el día 18 de agosto es muy descriptivo de los dramáticos momentos que se habían y se estaban viviendo².

Después del terremoto de Valparaíso, la reconstrucción no se aborda desde el punto de vista de una política fiscal. No obstante la cuantía de las pérdidas (30

2. Alfredo Rodríguez Rozas y Carlos Gajardo Cruzat. La catástrofe del 16 de agosto de 1906 en la República de Chile, Santiago, Imprenta y Litografía Barcelona, 1906, p. 180 y 55. 
millones de libras esterlinas de la época, en la estimación de Luis Zegers) ${ }^{3}$, no hay legislación especial, ni el Ejecutivo toma medidas al respecto. Se subentiende, en consecuencia, que los procesos de reconstrucción se abordarán con los recursos normales del Estado. Es cierto que en Valparaíso se constituyó una Junta de Reconstrucción y además se obtuvo un préstamo en Inglaterra. Sin embargo, como veremos a lo largo de este estudio, cada vez que se recurre a préstamos sin indicar la forma en que serán cancelados, significa que a la larga se pagarán con cargo a los ingresos fiscales del país. En consecuencia, no existe una política para enfrentar esta emergencia extraordinaria con recursos extraordinarios, cosa que sí ocurrirá más adelante.

Pareciera, entonces, que el financiamiento de la reconstrucción posterremoto cada cierto tiempo debe hacerse con cargo a los ingresos generales del país, lo cual obviamente significa postergar algún otro tipo de obras de adelanto que se pudieren hacer con dichos ingresos fiscales. Hay acá una concepción implícita de que estas catástrofes obligan a un mayor esfuerzo, a una reasignación de recursos, pero no a la elaboración de políticas concretas para enfrentarlas.

Pero sí hubo otro tipo de experiencias que se pueden extraer. En septiembre de 1907 el gobierno de Pedro Montt contrató al sismólogo francés conde Fernando De Montessus de Ballore como profesor y Jefe del Servicio de Observaciones Sismológicas. Se instalaron diversos observatorios sismológicos donde se generarían informes para el gobierno de Chile, y además se capacitaría a algunos científicos chilenos en esta especialidad. Con ello se funda el Instituto Sismológico, la institución más importante que deja el terremoto de 1906.

El otro elemento significativo es que antes del terremoto, en febrero de 1906, se dicta la Ley 1.838 de habitaciones obreras ${ }^{4}$. Esta ley era producto de un largo debate en el parlamento sobre la llamada "Cuestión Social". Permitía resolver el problema del hacinamiento en los conventillos en los cuales vivía buena parte de la naciente clase obrera en los inicios del proceso de urbanización en Santiago, Valparaíso, Concepción y otras ciudades. La utilización de esta ley permitió, luego del terremoto, iniciar una tarea muy importante:

"A raíz del terremoto en 1906, en Santiago y Valparaíso, hace crisis el problema de la insalubridad de la vivienda y el Congreso Nacional decide la promulgación de la ley $N^{\circ} 18.366$ que marca el comienzo de una intensa labor fiscal que iba a ser un hito en América Latina. Al amparo de esta ley se crea la Caja de Crédito

3. Luis L. Zegers. "El Terremoto del 16 de agosto", Anales de la Universidad de Chile, Tomo CXIX, julio-diciembre 1906.

4. Chile, un siglo de politicas en vivienda y barrio. Ministerio de Vivienda y Urbanismo, diciembre de 2004 , p. 60. 
Hipotecario (futuro Banco del Estado) que ejecuta entre 1911 y 1918 la población modelo 'Huemul' en una zona industrial de Santiago. El proyecto del arquitecto Ricardo Larraín Bravo interviene simultáneamente la división predial, el diseño de la vivienda y del equipamiento, con una coherencia y cualidad ambiental que hasta ahora es digna de aprecio. Su planificación incluía 157 viviendas, escuela, biblioteca, teatro, iglesia, policlínico y plaza de juegos. El diseño del barrio sigue la matriz de una mini ciudad, donde estaban integradas a la vivienda las funciones de servicio y de trabajo, a diferencia de los barrios jardín que vendrían a influir el diseño urbano habitacional en décadas posteriores. Con la creación de la Caja de la Habitación Popular en 1936 se da un nuevo impulso a la participación del Estado en la construcción de viviendas económicas"s.

Esta ley permitió, de acuerdo con Ferrada ${ }^{6}$, la construcción de viviendas para las clases trabajadoras tanto en Valparaíso como en Viña del Mar, que fueron un elemento importante en el proceso de reconstrucción tras el terremoto de 1906 extendiendo, de paso, el radio urbano de Valparaíso.

La Ley 1.838 estableció el Consejo de Habitación para Obreros, que tenía atribuciones porque era un organismo constructor. Sobre esta base se materializó una diversidad de tipologías como el conventillo, la cité, el pasaje y otros. Esta normativa tuvo un rol muy importante en la nueva configuración de la ciudad de Valparaíso, y bajo su amparo, como señala Ferrada, "se implementaron los primeros esquemas de población bajo un modelo planificado, masivos e higiénicos"7.

Además, inmediatamente producido el terremoto, el 3 de septiembre el Gobierno dispuso la formación de una comisión para estudiar la estabilidad en las futuras construcciones, para lo cual se comisionó al Director General de Obras Públicas. Los resultados de este estudio se publicaron recién en 1913 en el Boletín del Servicio Sismológico. Es esta una constante que se repite luego de cada terremoto: el analizar por qué las viviendas no resistieron, y cómo se puede hacer una construcción asísmica que resista futuros movimientos. Este primer informe es precursor de los trabajos que se desarrollarán, intensamente, como resultados de los siguiente terremotos.

5. Humberto Eliash y Manuel Moreno, Ciudad latinoamericana: ¿espacio de incomunicación? El caso chileno, en <www.dialogosfelafacs.net/dialogosepoca/pdf/23-07HumbertoEliash.pdf>, sitio web de Diálogos, Revista Académica de la Federación Latinoamericana de Facultades de Comunicación Social.

6. Ferrada, Mario, Valparaíso, 16 de agosto de 1906: El desastre que sirvió como motor de desarrollo, en Revista Ciudad y Arquitectura, No 126, agosto-septiembre de 2006, en <www.revistaca.cl>.

7. Ferrada, op.cit. 


\section{TALCA, 1 DE DICIEMBRE DE 1928}

Grado 8.0

Hora: minutos después de las 00:00 horas

Víctimas: 300 muertos.

Por primera vez luego de un sismo de esta naturaleza, el gobierno (Carlos Ibáñez del Campo, en su primera administración) dispuso una vacunación general contra la fiebre tifoidea.

Al igual que en 1906, no hubo una ley especial para abordar la catástrofe. Se hizo una colecta en donde la ciudadanía cooperó con algo más de 4 millones de pesos, comenzando con el Presidente de la República y los funcionarios de la administración pública que cooperaron con un día de sueldo. La ayuda inmediata estuvo coordinada por el Ministerio del Interior. Luego, nada más.

Es cierto que se ordenó la realización de un estudio para determinar por qué la destrucción fue tan masiva. La conclusión fue que "la magnitud de la destrucción se debió a la debilidades de las construcciones, más que a la violencia del sismo"8. Este informe fue importante para dictar en enero de 1929 la Ley $N^{\circ} 4.563$ que autorizaba al Presidente de la República para establecer las ordenanzas generales conteniendo las normas de construcción de los edificios, para poder enfrentar de una mejor manera futuras calamidades. Sin embargo, la filosofía fue la misma del terremoto de Valparaíso: no hay razón para tomar medidas especiales que apunten hacia una política general del Estado.

\section{CHILLÁN, 24 DE ENERO DE 1939 \\ Grado 8.0}

Hora: $23: 32$

Víctimas: 5.685. La prensa habla de 20.000 y otros aun de 30.000 .

Apenas un mes después de asumir como presidente, Pedro Aguirre Cerda debió enfrentar el terremoto de Chillán. Lo hizo con un patrón distinto. Decidió insertar el proceso de reconstrucción en un plan más general a partir de su concepción de lo que debía ser el desarrollo futuro de Chile.

Es la primera vez que de un modo explícito las tareas de la reconstrucción pasan a formar parte de un plan general de desarrollo, a partir de las consecuencias del terremoto y ante la necesidad de superar el drama de las provincias devastadas.

8. Rosa Urrutia, Carlos Lanza. Catástrofes en Chile 1541-1992. Santiago, Editorial La Noria, 1993, p. 210. 
Como resultado de esta decisión se establece una nueva institucionalidad. Se crean la Corporación de Reconstrucción y Auxilio y la Corporación de Fomento de la Producción (CORFO). El gobierno de la época hizo un enorme esfuerzo para tener promulgada la legislación correspondiente en un periodo de dos meses, en abril de 1939. La Ley 6.334 del 29 de abril de 1939 establece que la Corporación de Reconstrucción y Auxilio -dependiente del Ministerio de Hacienda- sería la encargada de reconstruir el sistema habitacional. Esta corporación tenía tres grandes objetivos: 1) la edificación de viviendas, otorgando préstamos a los damnificados para reconstruir o reparar edificios, o bien construyendo ella misma o a través de terceros mediante propuestas; 2) las obras de emergencia tales como pabellones y barracas para albergar a la población, servicios públicos y municipales de la zona afectada; y 3) las obras públicas municipales. La corporación se complementó más adelante con la Ley de la Caja de la Habitación (1943), dependiente del Ministerio del Trabajo. Se levantó "en las provincias de Talca a Malleco inclusive, 274 pabellones para viviendas conteniendo 2.113 departamentos, los que pese a su carácter de 'emergencia' subsistieron como alternativa habitacional hasta al menos 20 años más tarde"

La CORFO es sin duda la institución señera que aparece como resultado del terremoto de 1939. La idea de una Corporación de Fomento es anterior, por cierto, al terremoto y al gobierno de Pedro Aguirre Cerda. Aníbal Pinto señala que ello fue resultado de largas discusiones en el Instituto de Ingenieros de Chile, que comenzaron en el año 1935 o 1936. Fueron los miembros de esa institución quienes concibieron un proceso de industrialización como única salida para la crisis de 1929, planificando lo que serían los elementos básicos: la necesidad de energía eléctrica, la necesidad de provisión de acero, y la necesidad de otros elementos energéticos como el petróleo. El debate entre los ingenieros hizo que la idea de una Corporación de Fomento apareciera como relativamente madura para su incorporación en el proceso de reconstrucción a partir del terremoto.

Es sabido que dicha legislación se aprobó con un solo voto de mayoría en el parlamento. ¿Habría sido posible impulsar una reforma de esta envergadura, que implicaba un cambio fundamental en la orientación de la política económica, si no hubiese ocurrido el terremoto de Chillán con todas sus consecuencias económicas y sociales? El debate en el parlamento es muy interesante, en tanto deja clara la línea divisoria entre quienes pensaban que para impulsar las labores de

9. Citado por Ministerio de Vivienda y Urbanismo, Chile, un siglo de políticas en vivienda y barrio, p. $83-84$. 
industrialización era indispensable una palanca en manos del Estado, y quienes confiaban únicamente en el mercado interno.

Es desde la Corporación de Fomento que se planifica la creación de la Empresa Nacional de Electricidad, una empresa de carácter público para llegar con energía eléctrica a la inmensa mayoría del territorio nacional donde no existía interés por parte del sector privado. El sector privado (con capitales extranjeros) estaba concentrado en proveer la energía eléctrica para las grandes ciudades como Santiago, Valparaíso y Concepción, donde era un negocio rentable: la CORFO viene a romper ese esquema. A partir de la CORFO también se echan las bases de la gran industria del acero, la que tenía una incipiente fundición en Corral, y se traslada a las actuales instalaciones en la zona de Concepción. Y es también esta corporación la que crea la Empresa Nacional de Petróleo una vez que se descubre petróleo en Magallanes. Estamos, por tanto, frente a un caso clásico del terremoto reconvertido en oportunidad. ¿Habría sido posible para Pedro Aguirre Cerda obtener las mayorías parlamentarias para una legislación de esta envergadura? Seguramente no. En este caso, la tesis de este artículo en el sentido de que todo terremoto es una oportunidad, se demuestra plenamente.

Al igual que en Valparaíso en 1906, adquiere importancia la necesidad de un cierto planeamiento urbano: frente al terremoto de 1939, el Ministerio de Obras Públicas asume un papel pionero. Particularmente en el caso de Chillán, la definición de uso del suelo y la necesidad de trasladar la ciudad hacia su actual emplazamiento, obligan a una planificación urbana que en el pasado era prácticamente desconocida. Se comienza a hablar de los planos reguladores, a definir cuáles debieran ser los centros poblados y sus características. Esto tendrá un nuevo desarrollo a partir del terremoto de 1960.

La Ordenanza General de Construcciones, que se había elaborado en 1932 como una forma de sistematizar las normas de la construcción en el país, es modificada a partir de lo ocurrido en el terremoto de 1939, y un decreto de 1942 incluye especificaciones mucho más exigentes que las contenidas es la ordenanza original.

Para concluir, la visión de Pedro Aguirre Cerda que le permitió plasmar las bases del desarrollo futuro de Chile a través de una nueva institucionalidad como es la CORFO, es resultado directo del terremoto de 1939. Los autores coinciden en que sin esta catástrofe, ello habría sido imposible. Además, se fortalece la idea que en el proceso de "hacer ciudad" debe haber elementos reguladores y de planificación por parte de la autoridad central o comunal. Estos dos elementos van a marcar el desarrollo posterior, tanto en el terremoto de 1960 como en los de 1985 y 2010. 


\section{CONCEPCIÓN, 21 DE MAYO, y VALDIVIA, 22 DE MAYO DE 1960}

Grado 7.3 y 9.5 , respectivamente

Hora: Concepción a las 06:02 y Valdivia a las 15:11.

Víctimas: entre 2.000 y 12.000 muertos. Otras informaciones de prensa hablan de hasta $20 \mathrm{mil}^{10}$.

Como se sabe, el terremoto de 1960 es el sismo de mayor intensidad registrado en la historia. El subdirector del Instituto de Sismología de la Universidad de Chile de la época, Edgar Kausel, señaló que entre el 21 de mayo y los primeros días de junio se registraron 9 terremotos con epicentro en Chile, a lo que se sumó por cierto el devastador maremoto que ocurrió poco después de las 4 de la tarde del 22 de mayo. Luego, como resultado de un deslizamiento de tierra producido en el río San Pedro, se interrumpió el desagüe del lago Riñihue, lo que obligó a una operación de ingeniería que impidió el desborde de las aguas.

Se había establecido una cierta institucionalidad respecto de las catástrofes y existía ya el mítico $2 \%$ constitucional que podía girar el gobierno respecto del presupuesto nacional vigente. Fue precisamente lo que se hizo: el gobierno giró más de 4 millones 84 mil escudos de la época ${ }^{11}$. Una parte de esos fondos se pusieron a disposición de intendentes y gobernadores. Tal como había hecho en otras oportunidades, el presidente Alessandri actuó a título personal: donó mil colchones, mil frazadas y 5.900 chalecos de lana como forma de incentivar los aportes voluntarios ${ }^{12}$.

El terremoto de 1960 demuestra también que el planeta se "achica" como consecuencia de los avances tecnológicos, y aparece la idea de la solidaridad mundial, idea propia de un mundo que comienza a globalizarse. Se establece un gigantesco puente aéreo: Einsenhower, presidente de Estados Unidos, se dirige al pueblo norteamericano para que demuestre su generosidad con Chile y llegan entonces cerca de 30 "globemasters" directamente desde las bases estadounidenses en el Caribe, que transportaron cuatro hospitales desarmables, helicópteros, ambulancias, toneladas de alimentos, ropa y medicinas. Entre los helicópteros también se contaron dos aeronaves argentinas que sobrevolaban la zona del cataclismo, y los aviones Britania trajeron desde Gran Bretaña toneladas de artículos para la emergencia. Desde Mendoza y Bariloche llegaron también grandes apoyos por parte del gobierno argentino. Lo mismo hizo Perú, Cuba y muchos otros países.

10. La cifra de 12.000 muertes corresponde a AA.VV., Terremotos en Chile. Valparaíso, Chillán, Valdivia, Museo Histórico Nacional de Chile, Santiago, 2009, p. 118. Otras fuentes establecen un aproximado de 2.000 muertos.

11. Un escudo equivalía a un dólar de Estados Unidos.

12. El Mercurio, Cuerpo I, "Donación Particular Hizo S.E”, martes 24 de mayo, 1960, p. 1. 
En política exterior, la solidaridad se expresó a través de una iniciativa sui generis, notable para la época. El presidente de Venezuela, Rómulo Betancourt, propuso que todos los países de América contribuyeran con una ayuda de envergadura para Chile. Varios países adhirieron. Era sin duda una iniciativa compleja y difícil, pero ella habla de la forma que estaba tomando la ayuda internacional. Prácticamente todos los países se hicieron presentes. Alemania occidental planteó su particular interés en la reconstrucción de Valdivia. El Ministro del Interior de la República Federal de Alemania Gerhard Schröder llegó a Chile y se trasladó de inmediato a esa ciudad. Fue el inicio de la ayuda internacional con motivo de las catástrofes después de la Segunda Guerra Mundial. El planeta aparecía ahora como uno solo. Cada uno aportaba lo que podía: la Cuba de Fidel Castro ofreció azúcar y el representante hindú en nuestro país señaló que Nehru sabía que el pueblo chileno pasaba sus penas con una "tacita de té". Por ello el gobierno de India quería saber cuál era el consumo de té en las provincias castigadas, para poder obsequiar a sus habitantes el consumo de té por un año.

Al igual que Pedro Aguirre Cerda, Alessandri propuso una legislación especial para enfrentar el terremoto. Como resultado de esta legislación especial y tras encendidos debates en el Congreso, se llegó a establecer un conjunto de impuestos que en total implicaron una recaudación superior a los 100 millones de dólares. Al mismo tiempo, se autorizó al gobierno para endeudarse hasta por 500 millones de dólares, en tanto había conciencia de que los 100 millones recaudados por la vía fiscal serían insuficientes para paliar los costos de la reconstrucción. Para tener una idea de lo que implican 500 millones de dólares de la época parece útil recordar que el total de las exportaciones de la gran minería del cobre el año 1960 equivalía a 160 millones de dólares. Según el Banco Central de Chile, el Programa de Reconstrucción integrado en el plan general de desarrollo económico (que debía durar tres años), implicaba un costo de reposición de los bienes destruidos avaluado en 425 millones de escudos.

Para los efectos de los créditos se estableció que los intereses devengados de los bonos estarían exentos de cualquier gravamen fiscal. En virtud de esta ley, se autorizó al Presidente de la República a contratar directamente con gobiernos, organizaciones estatales, instituciones bancarias o financieras, extranjeras o nacionales, préstamos a largo o corto plazo. También se autorizó a emitir obligaciones de Tesorería a corto plazo, emitir bonos a corto y largo plazo y a otorgar la garantía del Estado a los préstamos o créditos que contraten en el exterior la CORFO o las municipalidades.

Todo esto da cuenta de que la forma de financiar la reconstrucción en 1960 fue, básicamente, el crédito. 
La ley otorgaba también otras facultades de carácter social al Presidente de la República. Por ejemplo, conceder subsidios mensuales por el monto de hasta un sueldo vital mensual del Departamento de Santiago a las familias de personas fallecidas a causa de los sismos de mayo de 1960, u otorgar durante los siguientes cinco años becas en los internados y medio pupilaje de los establecimientos fiscales de educación a los postulantes domiciliados en la zona de la catástrofe, aunque no reunieran los requisitos establecidos en los reglamentos vigentes para optar a dichas becas. Todo ello se estableció en la Ley 14.171 que, como se indicó, fue promulgada tras un largo y difícil debate el 20 de octubre de ese año. Como la ley demoraba en salir y era indispensable tomar algunas medidas de carácter urgente, Alessandri desglosó algunos artículos, lo que dio origen a la Ley 14.009 autorizando a ciertos institutos de previsión para conceder a sus imponentes préstamos de auxilio con motivo de la emergencia.

Hubo también un préstamo de dos millones de dólares para la reconstrucción, aprobado a partir de un informe que fue elaborado por CEPAL con datos de la CORFO y otros organismos públicos y privados. La Ley 14.171 modificó las normas del Ministerio de Economía y lo transformó en Ministerio de Economía, Fomento y Reconstrucción, atribuyéndole la tarea de:

"promover y coordinar la acción estatal para la elaboración de proyectos de fomento y desarrollo de las actividades del país y de los planes de reconstrucción de las zonas devastadas; promoción y coordinación de la inversión de los recursos fiscales, de administración autónoma y empresas del Estado, para orientarlas hacia los fines de reconstrucción; determinar el orden de prioridades de los planes de inversión del sector público"13.

Como se ve, hay una cierta continuidad con el planteamiento de Aguirre Cerda. No obstante el pensamiento más liberal en lo económico del presidente Alessandri, este entendía que debía haber un ente orientador para el sector privado, pero que fuese norma jurídica para el sector público respecto de la acción de inversión que se debía realizar. Al mismo tiempo, entendía que la reconstrucción estaba inserta en una forma más amplia de entender el desarrollo del país, y con ese fin se creó también el COPERE (Comité de Programación Económica y de Reconstrucción), integrado por los ministros de Economía, Hacienda, Obras Públicas, Minería, Agricultura, Vicepresidente y Gerente de CORFO, el Vicepresidente de la Corporación de la Vivienda y el Director de Presupuesto. Nótese que en esta enumeración de instituciones aparecen organismos nuevos de enorme poder como es el caso del Director de Presupuesto y el Vicepresidente de la Corporación de la Vivienda, continuadora

13. Rosa Urrutia, Carlos Lanza. Catástrofes en Chile 1541-1992. Santiago, Editorial La Noria, 1993, p. 301. 
de los ingentes esfuerzos que se venían haciendo en materia habitacional desde la ley de Habitaciones Obreras de 1906.

Producto del terremoto de 1960, se modificó también la Ley de Seguridad Interior del Estado, entregando al Presidente de la República la facultad de declarar Estado de Emergencia en zonas afectadas por graves desastres naturales o calamidades públicas, por una sola vez y por un plazo de hasta seis meses. Y se modificó también, por primera vez, la Ley de Donaciones: parecía absurdo que cuando el sector privado quería hacer aportes para enfrentar la catástrofe, tuviera además que pagar impuestos por su donación.

En el gobierno del Presidente Alessandri se había dictado, en 1959, el Decreto con Fuerza de Ley $\mathrm{N}^{\circ} 2$ para construcciones económicas destinadas a los sectores medios. Esta ley se acomodó como resultado del terremoto y permitió acelerar la construcción de viviendas.

Tenemos, entonces, dos características muy nítidas. Primero, hay un esfuerzo, tímido, es cierto, por recurrir al sistema tributario como una forma de financiar aproximadamente un 20\% del total del costo de la reconstrucción, en palabras del Ministro de Hacienda de la época. El resto se financiaría por la vía del empréstito, y como ya hemos anotado, el empréstito implica transferir la carga a las generaciones futuras: ellas deberán pagarlo. Por la vía del empréstito se prorroga el costo de la reconstrucción, pero salvo que a futuro haya nuevos recursos tributarios para pagarlo, ello se hará con cargo a las recaudaciones normales del Estado. En otras palabras, todos los chilenos deben pagar los costos de la reconstrucción, y no hay sectores obligados a pagar más en razón de su mejor situación.

Hay, así, una clara orientación de política económica que implica una mejora en tanto, por primera vez, hay un esfuerzo tributario. Pero las dimensiones del esfuerzo no se condicen con las necesidades globales generadas por la catástrofe.

\author{
SAN ANTONIO Y MELIPILLA, 3 DE MARZO DE 1985 \\ Grado 7.7 \\ Hora: 19:47 \\ Víctimas: más de 170 muertos.
}

La institucionalidad frente a las emergencias continúa su desarrollo. Así se crea la Oficina Nacional de Emergencia (ONEMI) en 1974, que depende del Ministerio del Interior y es la responsable de coordinar los distintos ministerios, servicios e instituciones voluntarias. Para efectos de este terremoto se creó un Cuartel General de Emergencia a cargo del Ejército. En los días siguientes al sismo hubo ciertas resistencias por parte del Ministerio del Interior y de los gobiernos regionales hasta 
que se logró compatibilizar el rol de ese Cuartel de Emergencia con los funcionarios civiles de esas reparticiones públicas. Lo anterior fue una buena demostración de cómo el régimen militar se hacía cargo de una emergencia de ese tipo. Por cierto, se mantuvo el Toque de Queda que ya regía en gran parte del territorio nacional.

Al momento de producirse el terremoto estaba en pleno desarrollo una discusión que había comenzado a partir de la gran crisis económica del 1982. Era un fuerte debate entre sectores que propiciaban políticas más proteccionistas y aquellos encabezados por el futuro ministro Hernán Büchi, que proponían entregar al mercado las grandes decisiones en el ámbito económico. Una buena parte de estas pugnas se vivió en el "periodo de la apertura" dirigido por el ministro Sergio Onofre Jarpa y donde el Ministro de Economía Luis Escobar Cerda se alineaba en el bando de los "proteccionistas".

Sin embargo, a partir de 1984 empiezan a tomar preeminencia las opiniones del Ministro de Hacienda Hernán Büchi. Ese año estableció una profunda modificación tributaria que, con el objeto de aumentar la inversión, establecía que el impuesto de las empresas se pagaría sobre las utilidades distribuidas y no sobre las utilidades efectivas o devengadas. De esta manera se inducía a las empresas a no pagar impuestos reinvirtiendo las utilidades o parte de estas. Así nació el Fondo Único Tributario (FUT) que subsiste hasta hoy. Algunas estimaciones señalan que el FUT alcanza a ser el equivalente a un producto nacional bruto de Chile durante un año. Una cifra monumental. En su momento fue una iniciativa llamada a tener éxito. Se trataba de recuperar la confianza luego de la crisis, se trataba de que los inversionistas volvieran a creer e invertir en Chile, para sacarlo de la profunda caída que la economía chilena había tenido en las crisis de 1982. Hay que recordar que ese año el producto bruto cayó un 14\% y el desempleo llegó a cerca del 20\%.

Es aquí donde el ministro Büchi habría visto que la oportunidad para avanzar en la agenda liberalizadora era precisamente el terremoto de marzo de 1985. Se trataba, como ha escrito un conocido periodista de la época, de "la oportunidad en medio del desastre". La necesidad de enfrentar la reconstrucción y al mismo tiempo continuar reactivando la economía, deben haber influido en sostener que, así como la reforma tributaria ayudaba, también ayudaba la forma en que se podía financiar la reconstrucción. Las discusiones terminaron. Como dice el columnista, "el sector proteccionista fue desplazado y todo lo que hasta entonces había parecido demasiado audaz o demasiado liberal adquirió una inesperada vigencia"14.

Esto fue lo que permitió avanzar en las privatizaciones en un número grande de empresas públicas. Las que se habían concretado antes del terremoto habían

14. Ascanio Cavallo, "La oportunidad en medio del desastre", en <www.uai.cl/201003096157/columna-de-opinion/columnas-opinion/la-oportunidad-en-medio-del-desastre>. 
avanzado lentamente. Ahora, so pretexto de buscar recursos para la reconstrucción, se pensó que si los privados podían realizar determinadas actividades, nada mejor que enajenar esos activos. Y por ello grandes empresas que estaban en poder de la CORFO, como la empresa de electricidad Endesa, ENTEL, Soquimich, Enaex, Laboratorio Chile, Iansa y CAP fueron traspasadas al sector privado. El terremoto se abordó y se enfrentó sobre la base de avanzar rápidamente en las privatizaciones. Tan rápidamente que ellas fueron objeto de gran debate tanto en el formato (la conveniencia de las mismas) como de la forma poco transparente de hacerlas. Muchos sectores productivos eran considerados estratégicos por parte de muchos militares. Pero en ese contexto, oponerse ya no fue posible. De igual manera, sectores que según algunos defendían "privilegios corporativos" y que se oponían a ello, también quedaron en el camino. Es tal vez el ejemplo más concreto de cómo las políticas públicas después de un terremoto normalmente ayudan a aquellos que, desde el gobierno, plantean la necesidad ante la emergencia de tomar medidas extremas.

En 1985 la convocatoria a la unidad nacional no se hizo esperar, y en esta oportunidad Mario Kreutzberger, Don Francisco, lideró la campaña "Chile ayuda a Chile". Era la emergencia de una nueva forma de enfrentar estos desastres: surgía la solidaridad masiva a través de grandes campañas mediáticas, y en especial, a través de la televisión.

\section{REGIÓN DEL MAULE Y CONCEPCIÓN, 27 DE FEBRERO DE 2010 Grado 8.8 \\ Hora: 03:34 \\ Víctimas: 521 muertos y 56 desaparecidos ${ }^{15}$.}

Al igual que en el terremoto de 1906, el de febrero de 2010 ocurre cuando ya hay un presidente electo que asume casi dos semanas después de acaecida la catástrofe. Luego de las labores de emergencia, las nuevas autoridades, encabezadas por Sebastián Piñera, inician un debate sobre la catástrofe y la forma que adoptará la reconstrucción. La toma de posesión del nuevo Presidente implicó una oportunidad para hacer un llamado a la unidad nacional ante la magnitud de la catástrofe: se trataba del quinto terremoto más fuerte del mundo. Sin embargo, la extensión del área donde se entendía que la placa Sudamericana había chocado con la de Nazca era superior a $350 \mathrm{~km}$, y eso explica que el 8.8 de magnitud en Concepción llegara a ser 7.8 y en algunas partes cercanas a 8 en la Región Metropolitana. El

15. ADN Radio Chile, 15 de mayo de 2010, Gobierno dio nueva cifra oficial de 521 muertos por el terremoto y tsunami <http: //www.adnradio.cl/nota.aspx?id=1298952>. 
mayor número de muertos fue resultado del maremoto que se produce después del terremoto, arrasando sectores enteros de la Región del Maule y de Concepción.

Las discusiones sobre la forma de abordar la reconstrucción y su financiamiento surgieron casi de inmediato. La propuesta original de la Concertación fue la necesidad de crear una agencia que se encargara de la reconstrucción, similar a la de 1939, la Corporación de Reconstrucción y Auxilio. El gobierno entendió que la institucionalidad existente era suficiente, y que a ello se sumaría la habitual coordinación entre los ministros. Por tanto, la idea de una institucionalidad especial para la reconstrucción fue desechada, y la discusión se centró en el financiamiento del proceso de reconstrucción.

De acuerdo a las estimaciones del gobierno, los daños eran superiores a los 20 mil millones de dólares. De estos, sin embargo, aproximadamente 8.500 millones de dólares es el costo que tendrá la reconstrucción desde el punto de vista del daño fiscal. El proyecto de reconstrucción enviado por el gobierno implicaba un aumento de los sistemas tributarios transitorios más una disminución de los impuestos, todo lo cual, de acuerdo a las cifras del gobierno debiera apuntar a 3.500 millones de dólares. Estos 3.500 millones de dólares se lograban mediante un aumento del impuesto que pagan las empresas de un $17 \%$ a un $20 \%$ por un año y medio. Conjuntamente con ello, había una disminución de carácter permanente del impuesto de timbres y estampillas, lo cual también fue objeto de un intenso debate. En efecto, la discusión del impuesto de timbres y estampillas venía de largo y en consecuencia había una disposición a disminuir el impuesto a la mitad. Además, el gobierno proponía aplicar un royalty a la gran minería del cobre y otras actividades mineras a partir del royalty que se había establecido en el año 2005. Esto implicaba que, como una forma de contribuir a la reconstrucción, se pagaba un royalty aumentado durante tres años y, a cambio de esto, se extendía la invariabilidad del sistema tributario desde el año 2017 al 2025.

Ambos temas eran controversiales. En lo tributario, porque la carga tributaria que ya es baja en Chile volverá a bajar, pues la reducción de impuestos es permanente y el aumento de impuestos es transitorio. En el royalty, en tanto éste grava el uso de un recurso que pertenece a todos los chilenos, lo lógico es que el destino del mismo sea la inversión, de suerte que cuando el recurso natural se agote las futuras generaciones de chilenos cuenten con una previsora inversión generada por el gravamen impuesto a dichos recursos naturales. Si se usan hoy para financiar el actual terremoto, ¿cómo se financiarán los terremotos futuros, si ya se han agotado los recursos naturales?

La oposición entendió que las cantidades que se pretendían recaudar eran insuficientes. Lo que estaba implícito era que los 5 mil millones de diferencia entre lo que se recaudaría por las nuevas disposiciones legales y el costo que la 
reconstrucción tenía para la caja fiscal, debía financiarse mediante préstamos nacionales o externos, expresados en moneda nacional o moneda extranjera. En otras palabras, esto significaba que a la larga esos 5 mil millones debían ser pagados por el presupuesto corriente de la nación.

Como se indicó anteriormente, el sistema tributario chileno en lo esencial mantenía la concepción de 1984 planteada por Hernán Büchi: los impuestos de las empresas se pagan sobre las utilidades distribuidas y no sobre las utilidades efectivas. Como resultado de ello, el sistema tributario chileno es absolutamente "neutral". Esto es, la distribución de ingreso en Chile permanece prácticamente inalterada antes y después del pago de impuestos.

Esto es absolutamente distinto de lo que ocurre con los países de la OCDE, organización de la cual Chile hoy forma parte, en donde la distribución de ingresos antes y después del pago de impuestos cambia drásticamente. En los países de la OCDE la distribución del ingreso antes del pago de impuestos es un GINI de 0.49 y después de impuestos es un GINI de 0.30. Es aquí (donde 1 es la desigualdad absoluta y 0 es la igualdad perfecta: cada 1\% del ingreso lo recibe el 1\% de la población) donde está uno de los elementos que explica la desigual distribución del ingreso en Chile: un sistema tributario inadecuado. Sin embargo, como lo dice muy bien la propia OCDE, es en el gasto fiscal donde se hace la diferencia. "Por ejemplo, en 2006 el ingreso neto de mercado del 10\% de las familias más ricas fue 31 veces superior que el del 10\% de las familias más pobres, pero sólo 12 veces mayor si se toma en cuenta su consumo de servicios sociales, salud y educación de financiamiento público"16. En otras palabras, el gasto fiscal es un elemento central en la política para mejorar la distribución de ingreso en Chile.

Dicho de otra manera, a partir de la forma de enfocar las políticas públicas por la Concertación en 1990 el gasto fiscal es el elemento que permite mejorar la distribución del ingreso, que se traduce en un aumento del gasto fiscal en salud, educación, prestaciones sociales, etcétera. Por lo tanto, el futuro financiamiento para pagar los créditos contratados por la vía del presupuesto ordinario, querrá decir que se está impidiendo el progreso del país respecto de los sectores más necesitados. O a la inversa, si el gasto fiscal va en beneficio de ellos, y ese gasto fiscal será para financiar el terremoto, querrá decir que en último término el financiamiento de esta catástrofe está en los sectores más débiles, que son los que se benefician del gasto fiscal. Este es el punto de divergencia entre gobierno y oposición. Digamos también que, al plantear el financiamiento con la privatización de algunos activos, se apunta en la dirección incorrecta. Si hay privatización de activos es para seguir

16. OECD (2010), Mejores Políticas de Desarrollo. Perspectivas OECD sobre Chile. OECD Publishing. <http: /dx.doi.org/10.1787/9789264095755-es>. 
invirtiendo y no para financiar terremotos, pero si entendemos el financiamiento del terremoto como una inversión, estamos equivocados, porque los terremotos terminan siendo un gasto corriente cada 20 años, pues estos ocurren cada tanto. Por ello no es adecuado financiar el terremoto con activos prescindibles que no estarán disponibles para financiar el próximo terremoto.

En suma, la discusión sobre el financiamiento del terremoto de 2010 es ilustrativa. Los sectores de la oposición plantearon la necesidad de mayores recursos como, por ejemplo, el aumento del royalty que al final se aprobó, de manera que el gobierno no tuviera que prescindir de activos, vale decir privatizar, ni incrementar el endeudamiento público, porque a la larga este se paga con los ingresos fiscales de futuros presupuestos. Se impide, así, aumentar el gasto para satisfacer las necesidades crecientes de la población. Por ello, cuando el gobierno del presidente Piñera plantea la necesidad de privatizar algunas empresas o algunos activos del Estado para financiar el terremoto, está avanzando su propia agenda, la que en su momento planteó al país.

Una vez más el terremoto es una oportunidad para poder plantear las políticas públicas que el gobierno que está en el poder y que debe tomar las decisiones del caso, desea impulsar. Pero no nos equivoquemos. La orientación de las políticas publicas, el diseño de los programas de gobierno, las tendencias en política económica y la estrategia para enfrentar los problemas de desigualdad social, gasto fiscal, rol del mercado, etcétera, se definen independiente de las catástrofes, naturales o humanas, que puedan afectar al país.

Sin embargo, cuando la tierra se remueve de manera tal que casi todo lo que estaba en pie se derrumba, no es sensato oponerse tenazmente a un programa de reconstrucción. La exacerbación de ese sentimiento de unidad nacional inunda todos los rincones de la ciudadanía, y la urgencia se impone ante cualquier idea de principio político. Por eso la idea de los terremotos como oportunidad, porque la urgencia y emergencia es lo único que se respira en los días posteriores a los terremotos, y el programa que está disponible y que tiene los medios -políticos y económicos- para implementarse es el del gobierno. Este ejecuta lo que siempre deseó hacer, solo que en estos casos se revisten con el caos y el desastre como escudo infranqueable.

Visto en perspectiva, lo más lógico es que ello se haga en función de un proyecto de futuro del país. Es esta visión de largo plazo lo que justifica al terremoto como una oportunidad.

Agradezco la colaboración de Alfredo Riquelme, Bárbara Silva y Joaquín Fernández en la investigación previa a la escritura de este artículo. Por supuesto, esa colaboración no los hace responsables de las conclusiones que aquí se obtienen. 


\section{REFERENCIAS BIBLIOGRÁFICAS}

Arriagada Luco, C., Cartier Rovirosa, E., Gutiérrez Vera, C., Sepúlveda Swatson, D. "Chile, un siglo de políticas en vivienda y barrio". Santiago, Ministerio de Vivienda y Urbanismo, diciembre 2004.

Cavallo, A. "La oportunidad en medio del desastre". <www.uai.cl/201003096157/columna-de-opinion/columnas-opinion/la-oportunidad-en-medio-del-desastre>. Universidad Adolfo Ibáñez. marzo, 2009.

"Donación Particular Hizo S.E". El Mercurio, Santiago, Chile, martes 24 de mayo, 1960. Cuerpo I, p. 1.

Eliash, H. y Moreno, M. "Ciudad latinoamericana: ¿espacio de incomunicación? El caso chileno". <www.dialogosfelafacs.net/dialogos epoca/pdf/23-07HumbertoEliash>. Revista Académica de la Federación Latinoamericana de Facultades de Comunicación Social.

Ferrada, Mario. "Valparaíso, 16 de agosto de 1906: El desastre que sirvió como motor de desarrollo". <www.revistaca.cl>, Revista Ciudad y Arquitectura, n 126, agosto-septiembre de 2006.

"Gobierno dio nueva cifra oficial de 521 muertos por el terremoto y tsunami". [En línea] ADN Radio Chile. 15 de mayo, 2010. <http: //www.adnradio.cl/nota.aspx?id=1298952>.

Lagos, Ricardo. "Chile respira profundo y encara la catástrofe". Diario Clarín, Buenos Aires, Argentina, 7 de marzo, 2010.

"Mejores Políticas de Desarrollo; Perspectivas OECD sobre Chile". [En línea] <http: /dx.doi.org/10.1787/9789264095755-es>.

Rodríguez Rozas, Alfredo y Gajardo Cruzat, Carlos. La Catástrofe del 16 de agosto de 1906 en la República de Chile. Santiago, Imprenta y Litografía Barcelona, 1906, pp.180 y 55.

"Terremotos en Chile. Valparaíso, Chillán, Valdivia". Santiago, Museo Histórico Nacional de Chile, 2009. p. 118.

Urrutia, R, Lanza, C. Catástrofes en Chile 1541-1992. Santiago, Editorial La Noria, 1993.

Zegers, Luis. "El Terremoto del 16 de agosto". Anales de la Universidad de Chile. Tomo CXIX, julio-diciembre (1906). 